\title{
Botulismo infantil. Comunicación de un caso clínico y revisión de la literatura
}

\author{
Daniela Arriagada S., Jan Wilhelm B. y Alejandro Donoso F.
}

\author{
Clínica Alemana - Universidad \\ del Desarrollo, Santiago, Chile \\ Facultad de Medicina, \\ Departamento de Pediatría (DAS) \\ Programa de Medicina Intensiva \\ Infantil (ADF) \\ Hospital Padre Hurtado, \\ Santiago, Chile \\ Unidad de Gestión Clínica del Niño \\ Área de Cuidados Básicos (JWB) \\ Área de Cuidados Críticos (ADF) \\ Recibido: 14 abril 2008 \\ Aceptado: 23 de octubre 2008 \\ Correspondencia a: \\ Alejandro Donoso Fuentes \\ adonoso@hurtadohosp.cl
}

\section{Infant botulism: Case report and review}

Botulism is a rare disease in Chile and of the known clinical presentation, infant botulism is the most common. We report the case of a previously healthy seven month old male infant with a two weeks history of rinorrea, cough, fatigue, constipation and progressive weakness after the consumption of honey. Stool cultures were positive for Clostridium botulinum group 1 type A and electromyography was compatible with the diagnosis. The patient evolved with arterial hypertension, interpreted as secondary to autonomic dysfunction, which responded to calcium channel blockers. Muscle tone improved progressively during the following four weeks. Infant botulism is a potentially fatal disease; diagnosis can be difficult given the broad clinical manifestations. Prevention should focus on education of parents of infants as well as medical personnell.

Key words: Infant botulism, Clostridium botulinum, honey.

Palabras clave: Botulismo infantil, Clostridium botulinum, miel.

\section{Introducción}

$\mathrm{E}$ 1 término botulismo proviene del latín botulus que significa salchicha. Su historia se remonta hacia el año 1820 , con las investigaciones realizadas por Justinus Kerner, sobre los envenenamientos producidos por salchichas con carne, conocidos como botulismo. Muchas hipótesis fueron postuladas sobre el agente causante de este cuadro clínico; sin embargo, no fue hasta el año 1897 cuando los microbiólogos Van Ermengem y Kempner demostraron que el botulismo era causado por la toxina de un bacilo anaerobio, que Van Ermengem denominó Bacillus botulinus ${ }^{1}$.

El botulismo es un trastorno neuroparalítico caracterizado por una parálisis fláccida descendente aguda, causado por la acción de la neurotoxina de Clostridium botulinum, bacilo grampositivo anaeróbico. Este agente contiene esporas subterminales y es capaz de generar ocho toxinas antigenicamente distintas (A, B, C1, C2, $\mathrm{D}, \mathrm{E}, \mathrm{F}$ y $\mathrm{G})^{2}$, de las cuales las toxinas $\mathrm{A}, \mathrm{B}, \mathrm{E}, \mathrm{y}$, en raros casos la $\mathrm{F}$, causan la enfermedad en humanos. De éstas, las toxinas A y B son las más descritas en el botulismo infantil.

Originalmente, tres formas de la enfermedad fueron reconocidas: alimentaria, de heridas o profunda, e infantil. Recientemente, tres nuevas formas han sido descritas: indefinida o no clasificada, inadvertida (rela- cionada con el uso terapéutico de toxina botulínica) e inhalada (bio-terrorismo) ${ }^{3}$. La forma infantil es la más frecuente.

El objetivo de esta comunicación es actualizar los conocimientos sobre esta patología tan poco frecuente, a través de la presentación de un caso clínico de un lactante, que tras la ingesta de miel, cursó con botulismo infantil.

\section{Caso Clínico}

Lactante de siete meses, sexo masculino, sin antecedentes mórbidos. Historia de dos semanas de coriza, tos y decaimiento. Recibió tratamiento con salbutamol, anti-inflamatorios no esteroidales y amoxicilina durante cinco días, sin mejoría de los síntomas. Tres días antes de ser ingresado, presentó exacerbación de la sintomatología respiratoria, mayor decaimiento, succión débil y llanto disfónico. Se hospitalizó con el diagnóstico de síndrome bronquial obstructivo. A su ingreso se describía afebril, normotenso, sin requerimientos de oxígeno, destacando al examen físico un sostén cefálico débil, ptosis palpebral, fuerza disminuida en las cuatro extremidades y escasa signología respiratoria. Los exámenes de laboratorio iniciales (perfil hematológico, PCR, sedimento de orina, electrólitos plasmáticos, gases venosos e inmunofluorescencia 
indirecta para virus respiratorios) fueron normales. Evolucionó con debilidad muscular progresiva, dificultad para alimentarse y constipación. En la evaluación neurológica destacaba un sostén cefálico débil, con dificultad para levantar la cabeza en prono, ptosis palpebral bilateral, pupilas isocóricas con reflejo fotomotor lento y ausencia de signos meníngeos ( $F i-$ gura 1). Se constató hipotonía de la cintura escapular y una sedestación inestable, vencimiento de la gravedad con extremidades y reflejos osteo-tendíneos sin alteraciones. Ingresó a la UCI para monitorización respiratoria. Se obtuvo el antecedente de ingesta de miel casera, tres días previos a su ingreso, destinada al alivio de la sintomatología (Figura 2). Se planteó el diagnóstico de botulismo, enviándose muestra de heces para cultivo e identificación de toxina al Instituto de Salud Pública, los cuales resultaron positivos para C. botulinum grupo I tipo A. Se realizó electromiografía que mostró un incremento anormal de los potenciales motores a partir de $20 \mathrm{~Hz}$, lo que evidenciaba bloqueo de placa pre-sináptica y denervación aguda generalizada, hallazgos compatibles con el diagnóstico planteado. Evolucionó sin progresión del compromiso muscular, ni requerimientos de oxígeno, pero con cifras tensionales arteriales sobre el percentil 95, atribuyéndose a disfunción autonómica. Se inició tratamiento con bloqueadores de canales de calcio, con respuesta adecuada, normalizándose la presión arterial a los pocos días. Se trasladó a sala con recuperación progresiva del tono muscular, e indicación de kinesioterapia motora y respiratoria. Pudo reanudar la alimentación por vía oral, luego de doce días de haberse empleado sonda nasogástrica. Fue dado definitivamente de alta a los 30 días de su ingreso. El control ambulatorio evidenció importante regresión de su sintomatología.

\section{Revisión}

Desde su reconocimiento como entidad clínica individual, en el año 1976, el botulismo infantil es la presentación clínica más frecuente de la enfermedad causada por la toxina botulínica. Sesenta por ciento de los casos reportados corresponden a esta forma ${ }^{4}$. En Chile, su notificación obligatoria se instauró en el año 2000, reportándose cuatro casos hasta el presente año $0^{5,6}$.

Todas las formas de botulismo causan la enfermedad a través de una vía común, independiente de la manera de adquisición de la toxina, ya sea desde el tracto gastrointestinal (vía circulación) o de una herida infectada (vía linfática), siendo transportada a las terminaciones neuromusculares donde bloquea la liberación de acetilcolina (vide infra). El botulismo infantil resulta de la ingesta de esporas de C. botulinum, que germinan, colonizan y producen in vivo la toxina en el tracto gastrointestinal. La toxina botulínica es absorbida en el lumen intestinal y transportada activamente a la circulación sistémica. Una vez en el torrente circulatorio, es distribuida a los sitios de neuro-transmisión mediada por acetilcolina donde produce su efecto tóxico. Bastan 0,3 ng de toxina en la unión neuromuscular para causar manifestaciones clínicas. Por su peso molecular $(150 \mathrm{kDa})$ no atraviesa la barrera hematoencefálica; los síntomas son limitados al sistema nervioso periférico, donde inhibe la liberación de acetilcolina mediante tres pasos: Se une en forma irreversible a los receptores pre-sinápticos colinérgicos de las terminaciones nerviosas motoras y parasimpáticas, la toxina o parte de ella es endocitada $y$, a través de su acción peptidasa, actúa sobre una o más de las tres proteínas SNARE (soluble N-ethylmaleimide sensitive fusion protein attachment receptor) e impide la fusión de la vesícula que contiene acetilcolina con la membra-

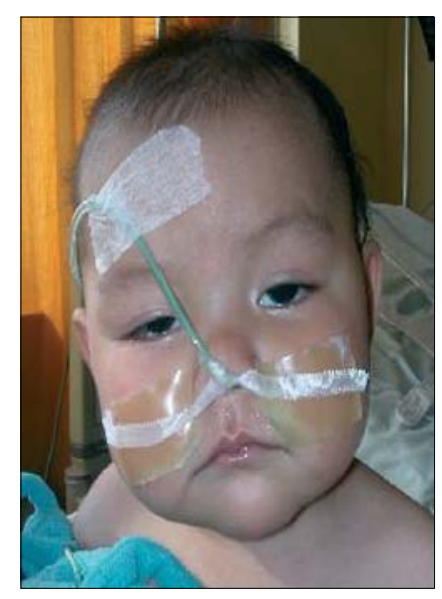

Figura 1. Lactante de 7 meses cursando con botulismo infantil. Se pude apreciar ptosis palpebral bilateral y alimentación por sonda nasogástrica dado la imposibilidad de deglución.

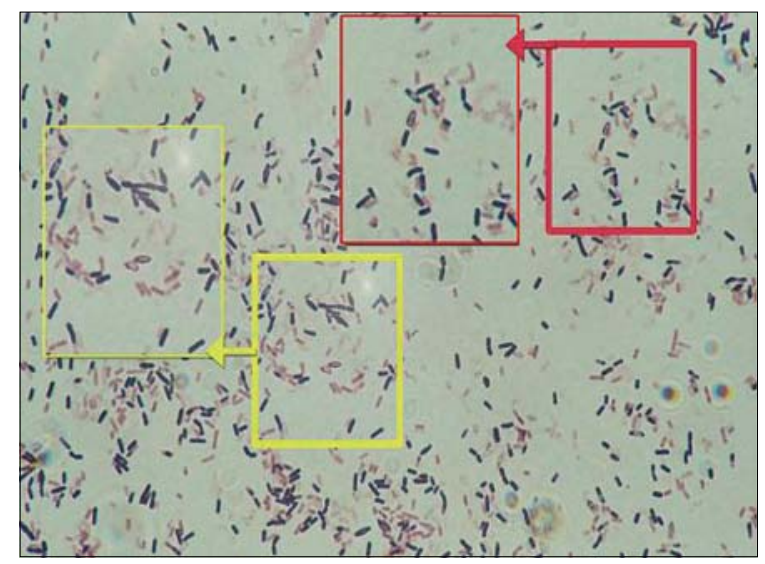

Figura 2. Se observa la morfología de Clostridium botulinum y sus esporas obtenidas de la miel ingerida por paciente de siete meses con botulismo infantil. Recuadro rojo esporas. Recuadro amarillo: bacilos. 


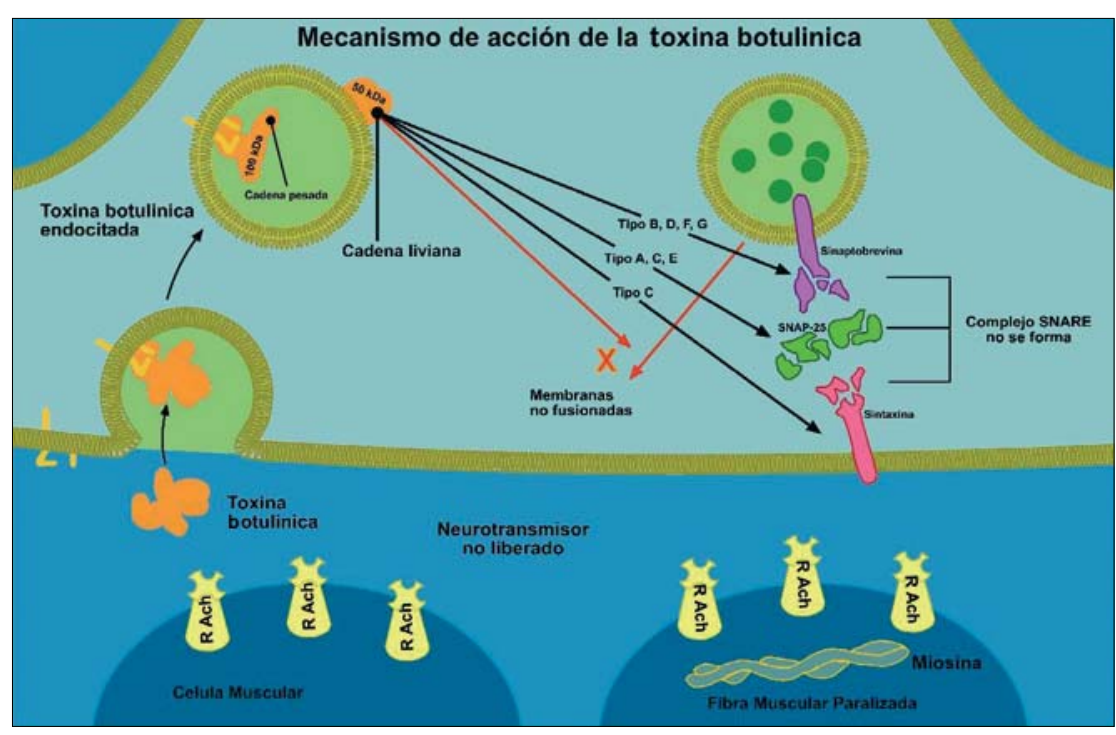

Figura 3. Representación esquemática del mecanismo de acción de la toxina botulínica.

na de la terminación nerviosa y la consecuente liberación de acetilcolina, bloqueando la transmisión de impulsos neuromusculares y vegetativos ${ }^{2,3,7}$ (Figura 3). La recuperación de la función nerviosa en las fibras musculares requiere la regeneración de las terminaciones nerviosas y formación de nuevas placas motoras.

La edad es un factor determinante en la suceptibilidad de los lactantes a esta enfermedad; se presenta desde los seis días de vida hasta los 12 meses de edad, ocurriendo la mayoría de los casos entre los dos y ocho meses. La información disponible sugiere que la vulnerabilidad de los lactantes refleja en parte, las prácticas de alimentación. Los niños con lactancia materna exclusiva reciben protección desde el calostro $\mathrm{y}$ tienen una microbiota suficientemente competitiva para inhibir el crecimiento de las esporas y producción de la toxina. Sin embargo, éstos son susceptibles durante la transición de lactancia materna a fórmula láctea o alimentos sólidos. Estos nuevos alimentos modifican la microbiota y aumentan el $\mathrm{pH}$ intestinal lo que favorece temporalmente el crecimiento de $C$. botulinum.

Las esporas de esta bacteria se encuentran ampliamente distribuidas en la naturaleza (suelos y sedimentos marinos) y aunque clásicamente la enfermedad se ha asociado con la ingesta de miel, en países como E.U.A. y Argentina, la mayoría de los casos ocurre por la ingesta de polvo que contiene esporas de C. botulinum $^{8,9}$.

La enfermedad generalmente es autolimitada, de evolución favorable y sin secuelas. Sin embargo, de no tratarse oportunamente tiene una alta letalidad (20$25 \%$ ), habitualmente causado por asfixia debido a la parálisis de los músculos respiratorios.

Miel y botulismo. Aunque en $85 \%$ de los casos la fuente de infección es desconocida ${ }^{10}$, con la excepción de una formula láctea recientemente asociada con botulismo ${ }^{11}$ la miel ha sido el único alimento reconocido como factor de riesgo significativo para esta enfermedad.

La miel puede contaminarse con esporas desde el ambiente, probablemente a través del polen y néctar depositado por las abejas, como también por la vestimenta e instrumentos utilizados por los apicultores. $\mathrm{La}$ muerte de las abejas y larvas, junto con el proceso de maduración, favorece el crecimiento de las esporas en la miel, especialmente en condiciones anaeróbicas creadas por el metabolismo oxidativo de Bacillus alvei, otro contaminante de la miel. Sin embargo, el pH ácido y el nivel de actividad del agua de la miel son inhibitorios para el crecimiento de C. botulinum. Las esporas, en cambio, permanecen viables; a diferencia de la toxina, son altamente resistente al calor, necesitando altas temperaturas $\left(>100^{\circ} \mathrm{C}\right)$ para su destrucción ${ }^{12,13}$.

Los tratamientos convencionales para destruir esporas no pueden ser utilizados en la miel, ya que producen cambios en la estructura de la fructosa, transformándola en hidroximetilfurfural (H.M.F), compuesto habitual en la miel, el cual si sobrepasa los $40 \mathrm{mg} / \mathrm{kg}$ de miel, altera las características organolépticas de esta, haciéndola no apta para el consumo humano ${ }^{12,13}$.

Cuadro clínico. La presentación clásica se caracteriza por historia de constipación (definido como tres o más días sin movimientos intestinales), que suele ser el primer y más frecuente síntoma, presente aproximadamente en $95 \%$ de los pacientes, seguido por dificultad para alimentarse, llanto débil, debilidad muscular progresiva, hipotonía, hiporreflexia y falla respiratoria. La debilidad muscular tiene un patrón característico: comienza con disfunción de los nervios craneales, derivando de este hecho la máxima de que "no existe botulismo infantil sin parálisis bulbar", para luego descender y afectar el tronco, extremidades y finalmente el diafragma (Tabla 1) 14-16. $^{16}$.

El sistema nervioso autónomo es usualmente afectado y sus manifestaciones preceden a la debilidad muscular. Los principales síntomas son mucosas secas, dilatación pupilar, alteraciones de la motilidad intestinal y vesical, inestabilidad de la presión arterial y arritmias.

El período de incubación es de 3 a 30 días. El inicio de los síntomas puede ser abrupto, en horas, o gradual, a lo largo de varios días, y su gravedad clínica puede ir desde síntomas poco prominentes hasta un proceso fulminante con evolución fatal que semeja el síndrome de muerte súbita (vide infra). Este espectro de gravedad está relacionado con el tipo de toxina (la 


Tabla 1. Manifestaciones clínicas
de botulismo infantil

toxina A da cuadros más prolongados y graves) y con la cantidad de esporas ingeridas, pues la toxina no unida se puede mantener circulante y unirse a las terminaciones nerviosas recién formadas, prolongando el tiempo de parálisis ${ }^{15}$.

La resolución de la enfermedad demora semanas hasta meses y se produce en orden inverso a su forma de presentación, siendo las manifestaciones autonómicas las últimas en desaparecer.

Botulismo y síndrome de muerte súbita. El botulismo infantil ha sido asociado con síndrome de muerte súbita, en 3 a 20\% de los casos. Sin embargo, la asociación entre muerte súbita y botulismo es controversial y puede variar con la prevalencia de botulismo infantil en una región. En un estudio en Alemania se documentó la presencia de toxina o del microorganismo en 15 de 72 casos de muertes infantiles inesperadas, mientras que en el sur de Australia, donde esta entidad clínica es poco frecuente, no se aisló $C$. botulinum en las deposiciones de 248 lactantes que fallecieron de muerte súbita ${ }^{4}$.

Diagnóstico diferencial. El botulismo infantil plantea problemas diagnósticos ya que su presentación es similar a otros cuadros clínicos. Los diagnósticos de hospitalización más frecuentes son los mencionados en la Tabla $2^{14,16,17}$. Estos pueden ser diferenciados por hallazgos clínicos y exámenes de laboratorio específi$\cos$.

La medición de electrólitos permite excluir alteraciones en el potasio o magnesio. La realización de una TAC de cerebro ayuda a excluir tumores o hemorra- gias. Si se considera una etiología infecciosa o postinfecciosa, debe realizarse una punción lumbar, y si en el LCR se encuentra proteinorraquia, ésta es sugerente de síndrome de Guillain-Barré, entre otros. La prueba de Tensilon ${ }^{\circledR}$ (administración intravenosa de edrofonio) ayuda a diferenciar el botulismo de la miastenia gravis, pero se han reportado pruebas falsamente positivas en aproximadamente $26 \%$ de los casos $^{2}$.

Diagnóstico. Debe sospecharse en base a los hallazgos clínicos y confirmarse con la identificación de la toxina y/o el microorganismo en las deposiciones o la presencia de toxina en el suero, resultando esta última rara vez positiva debido a la mínima cantidad de toxina botulínica circulante. Si se identifica $C$. botulinum en deposiciones, el diagnóstico es inequívoco ya que este microorganismo no es considerado parte de la microbiota intestinal residente. Con fines epidemiológicos, es importante analizar además alimentos sospechosos y muestras del ambiente.

La bio-cuantificación de neutralización de toxinas en ratones es considerada la técnica más sensible y de elección para el diagnóstico pero sus resultados pueden tardar varios días. Por ello, la eventual administración de la antitoxina debe iniciarse en base únicamente a la sospecha clínica. Para realizar un óptimo examen debe obtenerse una muestra adecuada de heces (aproximadamente 10 a $20 \mathrm{~g}$ ), pero si resultase de difícil obtención a consecuencia de la constipación, un enema con agua estéril no bacteriostática puede ser utilizado para lograr una muestra adecuada (al menos $25 \mathrm{ml}$ ).

Recientemente ha sido desarrollada la técnica de ELISA para la detección rápida de la toxina $\mathrm{A}$ y $\mathrm{B}$; sin embargo, su sensibilidad es 10 a 100 veces menor que la bio-cuantificación de toxinas en ratón ${ }^{18}$.

El estudio electrofisiológico es útil, rápido y apoya el diagnóstico. El signo característico es un incremento progresivo de los potenciales provocados con una

\begin{tabular}{l}
$\begin{array}{l}\text { Tabla 2. Diagnóstico diferencial de botulismo } \\
\text { infantil }\end{array}$ \\
\hline Sepsis bacteriana/meningitis \\
Alteraciones electrolíticas/deshidratación \\
Accidente cerebrovascular \\
Hipotiroidismo \\
\hline Errores innatos del metabolismo \\
\hline Poliomielitis \\
\hline Síndrome de Guillain-Barré (variante Miller Fisher) \\
\hline Miastenia gravis congénita \\
\hline Enfermedad de Werdnig-Hoffman \\
Intoxicación por organofosforados \\
\hline Intoxicación por metales pesados
\end{tabular}


estimulación de alta frecuencia de nervios (20 a $50 \mathrm{~Hz}$ ). Además, se observa un perfil característico de potenciales de acción motora francamente abundantes, de baja amplitud y breves. No obstante, si el estudio inicial es normal, no excluye el diagnóstico ${ }^{19}$.

Los exámenes de rutina como hemograma, sedimento de orina, urocultivo, citoquímico y cultivo de LCR, perfil hepático y metabólico son generalmente normales.

Tratamiento. Antitoxina botulínica. El tratamiento específico de botulismo es la administración de antitoxina botulínica, disponiéndose de dos tipos: la derivada de suero de caballo y la humana. Para que la antitoxina sea eventualmente beneficiosa debe ser administrada precozmente, mientras la toxina se encuentre en el plasma y antes de ser internalizada al terminal colinérgico pre-sináptico ${ }^{20}$

La antitoxina equina se encuentra disponible desde la década del 40' y es ampliamente utilizada. Sin embargo, su eficacia sólo ha sido evaluada en trabajos retrospectivos en las formas de botulismo clásico y por herida. No es recomendada para el tratamiento del botulismo infantil, por la alta tasa de reacciones de hipersensibilidad- ha sido reportada en $9 \%$ de los pacientes- y la corta vida media (5-8 días) de la antitoxina, la cual es considerada inadecuada para un síndrome causado por la absorción intestinal de la toxina botulínica ${ }^{4}$.

En octubre del 2003 la Food and Drug Administration (FDA) aprobó el uso de inmunoglobulina humana (BIG- IV), lo que significó un gran avance en el tratamiento del botulismo infantil. Su aprobación se basó en estudios que demostraron estadísticamente una reducción significativa en el tiempo de hospitalización (2,6 versus 5,7 semanas), tiempo de ventilación mecánica ( 1,8 versus 4,4 semanas), tiempo de hospitalización en unidad de cuidados intensivos $(1,8$ versus 5,0 semanas), tiempo de alimentación por sonda (3,6 versus 10 semanas) y costos de hospitalización ${ }^{21}$. En $14 \%$ de los lactantes tratados con BIG-IV y en $8 \%$ de los tratados con placebo se observó un exantema eritematoso inespecífico ${ }^{4}$.

La BIG es una solución intravenosa de inmunoglobulina $G$ humana purificada, con trazas de IgA e IgM, obtenida de plasma de dadores adultos previamente inmunizados con toxoide botulínico pentavalente. Su distribución y metabolismo es desconocido, pero su vida media ha mostrado ser aproximadamente de 28 días en los lactantes. Provee de una cantidad suficiente de anticuerpos para opsonizar y neutralizar los niveles esperados de neurotoxinas circulantes, por al menos seis meses. Los títulos de anticuerpos contra la toxina A son al menos $15 \mathrm{UI} / \mathrm{ml}$ y contra la toxina $\mathrm{B}$ $4 \mathrm{UI} / \mathrm{ml}^{21}$; sus picos de concentración se alcanzan rápidamente en la circulación. La concentración para las toxinas $\mathrm{C}, \mathrm{D}$ y $\mathrm{E}$ no ha sido determinada. La dosis recomendada es de $1 \mathrm{ml} / \mathrm{kg}$ peso $(50 \mathrm{mg} / \mathrm{kg})$ y debe ser administrada tan pronto como se sospeche. En nuestro país no se dispone de antitoxina botulínica humana.

Luego del reconocimiento de la enfermedad y administración de la antitoxina, es importante prevenir las complicaciones mientras se espera la recuperación neuromuscular. La observación en una unidad de cuidados intensivos con monitorización continua, por al menos 48 horas, es esencial para determinar la progresión y tratamiento de complicaciones.

El soporte nutricional y respiratorio es fundamental. La mayoría de los lactantes requiere de sonda nasogástrica o nasoyeyunal para alimentarse y asegurar un aporte calórico adecuado. El soporte respiratorio va desde un adecuado manejo de secreciones hasta ventilación mecánica en los casos más graves.

El uso de antimicrobianos no es recomendado ya que estos aumentan la cantidad de toxina en el intestino disponible para su absorción, como consecuencia de la lisis bacteriana, alteran la microbiota intestinal y permiten el sobrecrecimiento de $C$. botulinum. Deben evitarse especialmente los aminoglucósidos, clindamicina y medicamentos que contengan magnesio, ya que potencian el efecto bloqueador de la toxina ${ }^{22}$.

La constipación puede ser un problema y debe manejarse sólo con ablandadores de heces y aumento del aporte de líquidos, evitando el uso de laxantes. Estos pacientes excretan esporas y toxina junto con las heces hasta cuatro meses después de iniciado los síntomas, por lo que es de suma importancia un manejo cuidadoso de las excretas.

\section{Conclusión}

El botulismo infantil, si bien es una enfermedad rara en nuestro medio, exige un alto índice de sospecha y un diagnóstico precoz para iniciar el tratamiento oportuno y específico y así disminuir su morbi-mortalidad.

Es importante enfatizar medidas de prevención como son el evitar el consumo de miel en el primer año de vida y el fomento de la lactancia materna.

\section{Resumen}

El botulismo es un trastorno poco frecuente en nuestro país. De las formas conocidas, el botulismo infantil da cuenta de la mayoría de los casos. Comunicamos el caso clínico de un paciente de siete meses, sexo masculino, sin antecedentes mórbidos. Historia 
de dos semanas de coriza, tos y decaimiento. Tras la ingesta de miel presentó exacerbación de la sintomatología respiratoria, constipación y debilidad muscular progresiva. Se analizó muestra de heces resultando positiva para Clostridium botulinum grupo I tipo A. El estudio electromiográfico fue compatible con el diagnóstico. Presentó hipertensión arterial, atribuyéndose a disfunción autonómica, con buena respuesta a bloqueadores de los canales de calcio. Recuperó pro- gresivamente el tono muscular. En un control ambulatorio se apreciaba importante regresión de la sintomatología. El botulismo infantil es una enfermedad potencialmente letal de no tratarse oportunamente y de difícil diagnóstico, ya que su presentación es similar a otros cuadros clínicos. Es necesario educar a padres y personal médico sobre las medidas de prevención para los lactantes bajo doce meses de edad.

\section{Referencias}

1.- Ledermann W. Historia del Clostridium botulinum. Rev Chilena Infectol 2003; S39- S41.

2.- Nafissi S, Pourmand R. Current concepts in botulism: Clinical and electrophysiological aspects. J Clin Neuromuscul Dis 2003; 4: 139-49.

3.- Horowitz B. Botulinum toxin. Crit Care Clin 2005; 21: 825-39.

4.- Fox C, Keet C, Strober J. Recent advances in infant botulism. Pediatr Neurol 2005; 32: 149-54.

5.- Situación Nacional de las Enfermedades de Notificación Obligatoria Casos y Tasas, Chile 1998-2004. http://epi.minsal.cl/ evigant/Numero31/evigia/html/notific/ resum/resum1.htm. Julio 2007.

6.- Situación Nacional de las Enfermedades de Notificación Obligatoria Casos y Tasas. Chile 2005-2007.http:// epi.minsal.cl/evigia/ BEM\%2055.pdf. Julio 2007.

7.- Midura T. Update: Infant botulism. Clin Microbiol Rev 1996; 9: 119-25.

8.- Thompson J, Filloux F, Van Orman C, Swoboda K, Peterson P, Firth S, et al. Infant botulism in the age of botulism immune globulin. Neurology 2005; 64: 2029-32.
9.- Tornese M, Rossi M, Coca F, Cricelli C, Troncoso A. Epidemiología y factores de riesgo asociados al botulismo de los alimentos y al botulismo infantil: ¿Dónde y cuándo? Rev Chil Infectol 2008; 25: $22-7$

10.- Long S. Infant botulism. Pediatr Infect Dis J 2001; 20: 707-10.

11.- Brett M , McLauchlin J, Harris A, O'Brien S, Black N, Forsyth R, et al. A case of infant botulism with a possible link to infant formula milk powder: evidence for the presence of more than one strain of Clostridium botulinum in clinical specimens and food. J Med Microbiol 2005; 54: 769-76.

12.- Aureli P, Franciosa C, Fenicia L. Infant botulism and honey in Europe: a commentary. Pediatr Infect Dis J 2002; 21: 866-8.

13.- Subovsky M, Sosa A, Castillo A, Cano N. Evaluación del contenido de hidroximetilfurfural en mieles del NEA. XIII Reunión de Comunicaciones Científicas y Técnicas. Facultad de Ciencias Agrarias. Universidad Nacional del Nordeste, Argentina. Química Orgánica y Biológica 2002.

14.- Brook I. Infant botulism. J Perinatol 2007; 27: $175-80$.
15.- Córdova G, Rodríguez J. Caso clínico: botulismo infantil. http://escuela.med.puc.cl/ publ/boletin/20051/articulo8.pdf. Julio 2007

16.- Cox N, Hinkle R. Infant botulism. Am Fam Physician 2002; 65: 1388-92.

17.- Marie A, Arnon F, Arnon S. Clinical mimics of infant botulism. Pediatrics 2007; 119: 826-8.

18.- Lindström M, Korkeala H. Laboratory diagnostics of botulism. Clin Microbiol Rev 2006; 19: 298-314.

19. - American Academy of Pediatrics. Clostridial infections. Botulism and infant botulism (Clostridium botulinum). In Pickering LK, Baker CJ, Long SS, McMillan JA, eds. Red Book 2006 Report of the Committee on infections Diseases. $27^{\text {th }}$ ed. Elk Grove Village, Il: American Academy of Pediatrics 2006; 257-60.

20.- Mellado P, Court J, Mellado L. Botulismo. http://escuela.med.puc.cl/publ/cuadernos/ 2006/Botulismo.pdf. Julio 2007.

21.- Arnon S, Schechter R, Maslanka S, Jewell N, Hatheway C. Human botulism immune globulin for the treatment of infant botulism. N Engl J Med 2006; 354: 462-71.

22.- Moline N, Kemeny T, Ferreiro E. Botulismo en una lactante. Rev Chil Pediatr 1996; 67 (1): $10-2$ 